\title{
ANÁLISE DO SISTEMA VIÁRIO DO BAIRRO CENTRO DA CIDADE DE SÃO JOÃO DO RIO DO PEIXE/PB
}

\author{
ANALYSIS OF THE NEIGHBOR TRAVEL SYSTEM OF THE CITY \\ CENTER OF SÃO JOÃO RIO PEIXE / PB
}

\author{
Francisco Cleanto de Morais ${ }^{1}$ \\ Mirela Davi de Melo $^{2}$ \\ André Ferreira Costa ${ }^{3}$ \\ Melina Cavalcanti de Melo Bichinho ${ }^{4}$ \\ Camilla Furtado de Figueiredo ${ }^{5}$ \\ Pollyanna Priscila de Souza Lima ${ }^{6}$
}

\footnotetext{
${ }_{1}^{1}$ Graduando em Arquitetura e Urbanismo pela Faculdade Santa Maria.

${ }^{2}$ Possui graduação em Arquitetura e Urbanismo pela Universidade Federal da Paraíba (UFPB 2016), especialização em Gestão de Políticas do Patrimônio Cultural pela Faculdade Maurício de Nassau (2018) e mestrado em Desenvolvimento Urbano (MDU) pelo Departamento de Arquitetura e Urbanismo da Universidade Federal de Pernambuco (UFPE - 2019), canalizando seus estudos para o projeto paisagístico e o bem-estar. Exerce o cargo de arquiteto como técnica na Prefeitura Municipal de Marí/ PB desde 2016, atuando na elaboração de projetos arquitetônicos e urbanos. É docente na Faculdade Santa Maria (FSM) desde 2018.

${ }^{3}$ Desde 2016 é professor da Faculdade Santa Maria de Cajazeiras, atuando no curso de Arquitetura e Urbanismo e no curso de Engenharia Civil. Possui graduação em Engenharia Civil pela Universidade Federal da Paraíba (2014), graduação em Construção de Edifícios pelo Instituto Federal de Educação, Ciência e Tecnologia da Paraíba (2014) e especialização em Gerenciamento de Projetos pela Fundação Getúlio Vargas (2016). Tem experiência profissional na área de Engenharia Civil, com ênfase em Gerenciamento e Execução de Obras.

${ }^{4}$ Possui graduação em Arquitetura e Urbanismo pela Universidade Federal da Paraíba (UFPB 2016), especialização em Gestão de Políticas do Patrimônio Cultural pela Faculdade Maurício de Nassau (2018) e mestrado em Desenvolvimento Urbano (MDU) pelo Departamento de Arquitetura e Urbanismo da Universidade Federal de Pernambuco (UFPE - 2019), canalizando seus estudos para o projeto paisagístico e o bem-estar. Exerce o cargo de arquiteto como técnica na Prefeitura Municipal de Marí/ PB desde 2016, atuando na elaboração de projetos arquitetônicos e urbanos. É docente na Faculdade Santa Maria (FSM) desde 2018.

${ }^{5}$ Graduada em Arquitetura e Urbanismo pela Universidade Federal da Paraíba (2014), pós-graduada Habitação Social e Direito à Cidade pela Universidade Federal da Bahia (2016), pós-graduada em Arquitetura, Gestão e Construção de Edificações Sustentáveis pela Faculdade Unyleya (2016), mestre em Engenharia de Energias Renováveis com dissertação voltada para a pesquisa de alternativas de materiais de construção sustentáveis pela Universidade Federal da Paraíba (2017). Atualmente, é docente da Faculdade Santa Maria (FSM) e no Centro Universitário de João Pessoa (UNIPE), ambos no curso de Arquitetura e Urbanismo.

- Arquiteta e Urbanista graduada pelo Centro Universitário de João Pessoa - UNIPÊ. Mestre em Qualidade do Ambiente Construído pelo Programa de Pós-Graduação em Arquitetura e Urbanismo PPGAU-UFPB. Atualmente é professora do curso de Arquitetura e Urbanismo da Faculdade Santa Maria e Faculdade Paraíso do Ceará- FAP atuando principalmente nos seguintes temas: bioclimatismo na arquitetura e urbanismo, Sustentabilidade, conforto ambiental das edificações, simulações computacionais, história da arquitetura moderna e contemporânea e Plataforma BIM.
} 
RESUMO: A malha urbana não é formada apenas pelas áreas edificadas e áreas livres que se relacionam entre si, mas pelo conjunto de infraestrutura urbana que compõem um espaço urbano o qual é adaptado ou transformado conforme sua forma e função dentro da malha urbana, para suprir as necessidades e desejos de deslocamento da população. Segundo a historiografia do urbanismo, nas últimas décadas ocorreram mudanças físicas no Sistema Viário das cidades, o que gerou a necessidade de estudá-los. O objetivo deste trabalho é analisar a infraestrutura do sistema viário do bairro centro da cidade de São João do Rio do Peixe/PB. E para se alcançar este objetivo à pesquisa se insere no âmbito teórico da área do urbanismo, infraestrutura urbana e consulta das normas que regulamentam o sistema viário, sendo de natureza aplicada, foram adotados procedimentos metodológicos como: Pesquisa bibliográfica e documental, levantamento fotográfico e visitas in loco, para reunir termos e conceitos utilizados pela bibliografia para conceituar urbanismo, infraestrutura urbana e suas relações com o sistema viário. Com base nessa bibliografia e no método de Mascaró (2005), DNIT (2016) e DNER (1979), analisouse o sistema viário do bairro centro da cidade de São João do Rio do Peixe/PB, o qual não se encontra adequado conforme a metodologia adotada. No entanto essa relação entre sistema viário e pedestre flui de forma que não inviabiliza o convívio diário, pois as pessoas circulam e desfrutam do seu direito de ir e vir, de acordo com suas necessidades. A relevância dessa pesquisa se dá nos âmbitos social e acadêmico, no social, por contribuir com os órgãos públicos, por fornecer-lhes a real logística da malha viária do bairro e suas particularidades, para que estes tracem suas propostas para o sistema viário; e no acadêmico, pela ampliação do conhecimento de forma sistemática e teórica dentro das vertentes do urbanismo, infraestrutura urbana, sistema viário e qualidade de vida.

DESCRITORES: Infraestrutura urbana, Análise de vias, Sistemas urbanos.

ABSTRACT: The urban network is not only formed by the built-up areas and free areas that are related to each other, but by the set of urban infrastructures that compose an urban space where it is adapted or transformed according to its form and function within the urban network, to supply the needs and desires of population displacement. According to the historiography of urbanism, in the last decade physical changes occurred in the City's Road System, which generated the need to study them. The objective of this work is to analyze the infrastructure of the road system of the downtown neighborhood of São João do Rio do Peixe/PB. And to obtain these results, the research is inserted in the theoretical scope of urban planning, urban infrastructure and consultation of the norms that regulate the road system, being of an applied nature, where methodological procedures were adopted such as: Bibliographical and documentary research, photographic survey and visits in loco, to gather terms and concepts used by the bibliography to conceptualize urbanism, urban infrastructure and its relations with the road system. Based on this bibliography and the method of Mascaró (2005), DNIT (2016) and DNER (1979), the road system of the downtown neighborhood of São João do Rio do Peixe / PB was analyzed, which is not available the methodology adopted. However, this relationship 
between road and pedestrian systems flows in a way that does not make daily living unfeasible, as people circulate and enjoy their right to come and go according to their needs. The relevance of this research is social and academic, and in the social sphere, to contribute to public agencies, providing them with the real logistics of the neighborhood's road network and its peculiarities, so that they draw their proposals for the road system, and in the academic sphere, in the expansion of knowledge in a systematic and theoretical way within urbanism, urban infrastructure, road system and quality of life.

DESCRIPTORS: Urban infrastructure, Analysis of roads, Urban systems. 


\section{INTRODUÇÃO}

O crescente desenvolvimento urbano e a acumulação populacional nas grandes cidades são consequências da migração do homem oriundo de espaços rurais para espaços urbanos. Segundo o Censo Demográfico de 2010 do Instituto Brasileiro de Geografia e Estatística, (IBGE), cerca de $84 \%$ da população brasileira que residem em áreas urbanas necessitam de uma gestão de infraestrutura urbana mais eficiente, que forneça à população melhor qualidade de vida.

Esse aumento populacional causado pelo processo de migração, segundo Baeninger (2010), gerou o aumento de problemas sociais que se processaram de forma rápida e sem planejamento em torno dos grandes centros urbanos. É válido destacar que esse processo se manteve crescente até a década de 70 , enquanto que nas décadas de 80 e 90 constatou-se uma queda ou pausa desse crescimento, pois o cenário nacional passou a ser influenciado por fatores econômicos e políticos que atuaram no processo de desenvolvimento urbano, onde as metrópoles continuaram a crescer e a desempenhar um papel decisivo na formação do cenário urbano nacional.

O déficit da infraestrutura urbana no Brasil se desenvolveu associado à forma de como se deu o seu urbanismo, esse déficit com o passar dos anos promoveu transformações na infraestrutura, mesmo o país tendo vivenciado algumas experiências no campo de planos urbanísticos, as quais tentaram retardar ou impedir o crescimento de forma ordenada, que promoveriam aumento de problemas urbanos, e condicionarão a população a conviver com seus efeitos como, por exemplo: poluição, insegurança, desigualdade social, infraestrutura urbana deficitária com ênfase no sistema viário, que se desenvolveu de forma desarticulada, confusa e conflitante.

Para Mascaró (2016), a integração múltipla entre os subsistemas, facilita a formulação de novas políticas onde as necessidades de deslocamento nas linhas de desejo passam a ser consideradas no planejamento viário. 
O planejamento da rede viária é de suma importância dentro de uma proposta urbanística, visto que o sistema viário é formado por uma ou mais redes de circulação e complementado pela rede de drenagem pluvial. Seu custo é o mais elevado dentre os demais sistemas, o mesmo representa cerca de $50 \%$ do custo total do serviço de urbanização, pois ocupa de $20 \%$ a $25 \%$ do solo (MASCARÓ 2016), entendendo-se o que dificulta sua expansão e sua avaliação por partes dos seus usuários.

Essa realidade é vivenciada pelas cidades de pequeno porte, como no caso da cidade de São João do Rio do Peixe /PB, com uma população, segundo dados do IBGE (2010), de 18.201 habitantes, pois associado a esses fatores tem que ser considerado os fatores que Ihes são peculiares como a passagem da BR 405 pelo bairro centro. Essa relação entre esses fatores supracitados nos conduz a analisar o sistema viário do bairro centro da cidade de São João do Rio do Peixe/PB.

A ausência de pesquisa relacionada à malha viária da cidade de São João do Rio do Peixe /PB, principalmente no bairro Centro, o qual concentra o comércio do município e por ele passa o maior fluxo de veículos automotivos e pedestres, haja vista, a via urbana principal do bairro ser a Rua José Cândido Dantas pela qual passa a BR 405, que liga o Estado do Rio Grande do Norte ao Estado da Paraíba. Este trabalho visa a estudar a malha viária desde sua origem, seu desenvolvimento até a situação atual, contribuindo assim com a academia e com os órgãos públicos, ao fornecer-lhes a real percepção do sistema viário do bairro, para que estes possam traçar suas propostas de intervenção, de modo a visar a melhorarias do nível de qualidade de vida no bairro.

\section{METODOLOGIA}

O trabalho se insere no âmbito teórico da área do urbanismo, infraestrutura urbana e consulta das normas que regulamentam o sistema viário, possuindo natureza aplicada. Adotaram-se alguns procedimentos metodológicos como: Pesquisa bibliográfica, documental, levantamento fotográfico e visitas in loco, com o 
objetivo de reunir termos e conceitos utilizados pela bibliografia referente a urbanismo, infraestrutura urbana e suas relações com o sistema viário, para a partir de então analisar o objeto de estudo, fundamentado em parâmetros metodológicos que possibilitem analisar o sistema viário do bairro centro da cidade de São João do Rio do Peixe /PB.

Identificou-se a origem e evolução da infraestrutura urbana, seu desenvolvimento abstraindo assim conceitos como os de cidade, planejamento urbano e infraestrutura, que auxiliarão na construção e análise da pesquisa, uma vez que o sistema viário se relaciona com os outros subsistemas urbanos com graus de intensidade diferentes.

Constatou-se a composição do bairro. 01(uma) via arterial principal a Rua José Cândido Dantas pela qual passar a BR 405, que liga o Estado do Rio Grande do Norte ao Estado da Paraíba, conectada a vias coletoras e vias locais.

A investigação documental iniciou-se pela Prefeitura Municipal de São João do Rio do Peixe/PB, o que se encontrou nos arquivos foi a Lei Municipal sob o no 903/2003, que institui o Código de Postura do Município. Diante dessa situação passou-se a investigação para o município vizinho de Cajazeiras/PB, o qual possui a Lei Municipal sob o № 644/76, que dispõe sobre a Legislação Urbanista do Município e o Plano Diretor, datado de 1978. Ambas as proposições trabalham o sistema viário de forma superficial e vaga, o que nos conduziu a considerar o material como fonte secundária de informações na construção dessa pesquisa.

O bairro em estudo segundo Galvão (2011) está inserido na bacia do Rio do Peixe, situada no extremo oeste do Estado, compreendendo três sub-bacias: a de Souza, a de Brejo das Freiras e a de Pombal, com uma área total de $1.250 \mathrm{Km}^{2}$. A área territorial do município é de $474 \mathrm{~km}^{2}$, limitando-se com os seguintes municípios circovizinhos: Santa Helena (22 km), Cajazeiras $(21 \mathrm{~km})$, Nazarezinho $(25 \mathrm{~km})$, Marizópolis (17,5 km), Sousa (24 km), Vieirópolis (27 km), Uiraúna (24 km), Poço de José de Moura $(16 \mathrm{~km})$ e Triunfo $(25 \mathrm{~km})$, conforme anexo A, com outras informações importantes que influenciam o desenvolvimento do bairro em estudo como: delimitação e macrozoneamento da zona urbana e rural com seus distritos e localidades que se destaca por concentrar a maior parte da população, conforme 
censo demográfico do (IBGE 2010); rodovias pavimentadas; implantadas; de leito natural; os rios e açudes.

\section{RESULTADOS}

É através do processo de urbanização que o município revela suas relações setoriais, conforme afirma Braga \& Carvalho (2004, p. 12) "Com o crescimento da cidade, os usos tendem a se tornar conflitantes entre si e a saturar a capacidade de suporte da infraestrutura urbana e do meio ambiente".

Em entrevista cedida à pesquisa, o historiador Rogério Cândido Ramalho Galvão (2018), cita outros fatores que impulsionaram essa expansão como: a construção da ponte Dom Moises Coelho (1959), sobre o Rio do Peixe; a implantação de escolas estaduais (1970); a construção da PB 393 que liga a sede do município de São João do Rio do Peixe/PB a estância Terminal Brejo das Freiras (1978) e a outros municípios; A construção da unidade de saúde e Hospital João Dantas Rothéa, Do Sindicato dos Trabalhadores Rurais, Do Fórum Municipal, juntamente com os bairros, Senhor Alexandre e Populares e pela construção da Casa de Saúde Nossa Senhora de Fátima em 1963, no Bairro da Estação.

A delimitação do bairro centro da cidade de São João do Rio do Peixe/PB é demonstrada no apêndice B. O mapa da delimitação do bairro traz informações como a forma de arruamento que se processa no bairro em estudo, a área consolidada da zona urbana do município ( $98,5 \mathrm{ha}$ ), a distribuição dos equipamentos comunitários da zona urbana do município.

O bairro em estudo concentra o núcleo histórico do município (IPHAEP Instituto do Patrimônio Histórico e Artístico Estado da Paraíba - Decreto Estadual 22917/2002); A maior parte do comércio da zona urbana; Os serviços particulares; As instituições financeiras como Bancos, do Brasil e Bradesco; As instituições públicas como: Agência dos Correios; Terminal rodoviário; Casa de saúde; Hospital; Escritório da Telemar; Cartório; Ministério público; Estação ferroviária; Escolas 
estaduais e municipais; Mercado público; A praça da matriz e a Igreja Nossa Senhora do Rosário.

O sistema viário do bairro é formado por uma via arterial principal, vias coletoras e vias locais. A via arterial principal é a Rua José Candido Dantas (evidenciada no mapa viário pela a cor magenta), rua pela qual passa a BR 405 vindo do Rio Grande do Norte, essa passagem impulsiona o desenvolvimento do bairro, mas também gera pontos de conflitos que atuam em graus de intensidades diferentes a condicionar aos moradores e as pessoas que por ali trafegam o convívio com seus efeitos. As vias coletoras são destacadas pela cor amarela, já as vias locais são evidenciadas pela cor azul escuro. O Rio do Peixe é destacado pela cor azul claro. $O$ bairro possui ruas não pavimentadas e o mesmo também acomoda pontos de moto-táxi e de táxi localizados nas proximidades da Praça da matriz e terminal rodoviário.

O bairro em estudo fica localizado no centro da cidade de São João do Rio do Peixe/PB, é composto por uma malha urbana com (18) dezoito vias locais; (04) quatro vias coletoras e (01) uma via arterial principal por onde passar a BR 405, conforme apêndice C.

As vias locais do bairro Centro da cidade de São João do Rio do Peixe/PB possuem características semelhantes e cumprem suas finalidades. As vias locais do bairro centro são: Rua José Henrique Sobral, Rua Cel. José de Freitas, Rua Líbio Brasileiro, Rua Lúcio Duarte, Rua Lourival Ribeiro da Nobrega, Rua Irinéia Dantas Rocha, Rua Jornalista Laurenio Firmeza, Rua Maria Angélica, Rua Padre Joaquim de Sá, Rua Padre Cicero, Rua Vereador Antônio Amador Dias, Rua Tiradentes, Rua Manoel B. de Souza, Rua Lacordeiro F. Dantas, Rua José G. da Silva, Rua Sergio Ribeiro Maciel, Rua Rui Barbosa, Rua Genézio Furtado Leite, Rua Antônio Gonçalves, Rua Manoel S. Formiga e Rua 05 de Agosto.

A análise da Rua Jornalista Lauree Firmesa, objeto do corte espacial, foi realizada com base no método de Mascaró (2005), conforme figura 1. 
Figura 1 - Características das Vias Locais.

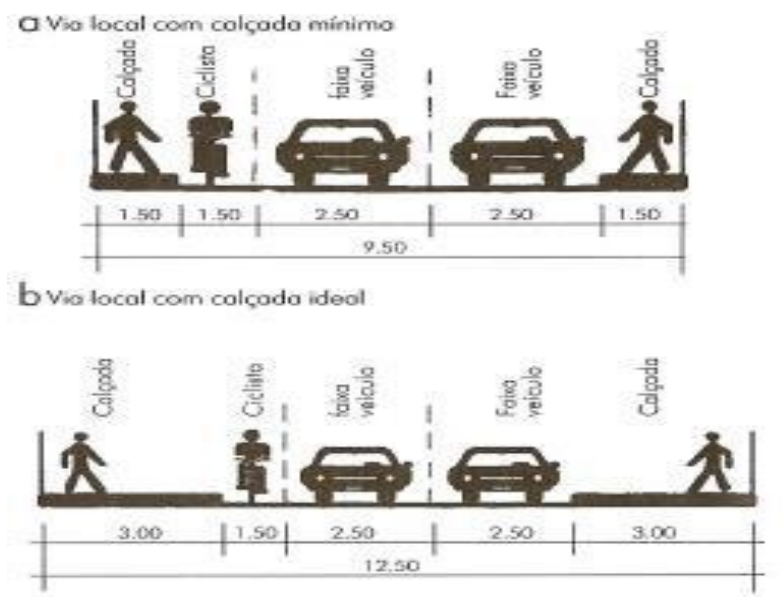

Fonte: MASCARÓ, 2005.

O C1 realizado na rua local Jornalista Lauree Firmesa conforme apêndice E. Demonstra que a via local do bairro possui calçadas de um lado com 2,15m e do outro $1,68 \mathrm{~m}$, atendendo assim os limites mínimos estabelecidos pelo método de Mascaró (2005). Conforme figura 2.

Figura 2 - C1 da Rua Local Jornalista Lauree Firmesa.

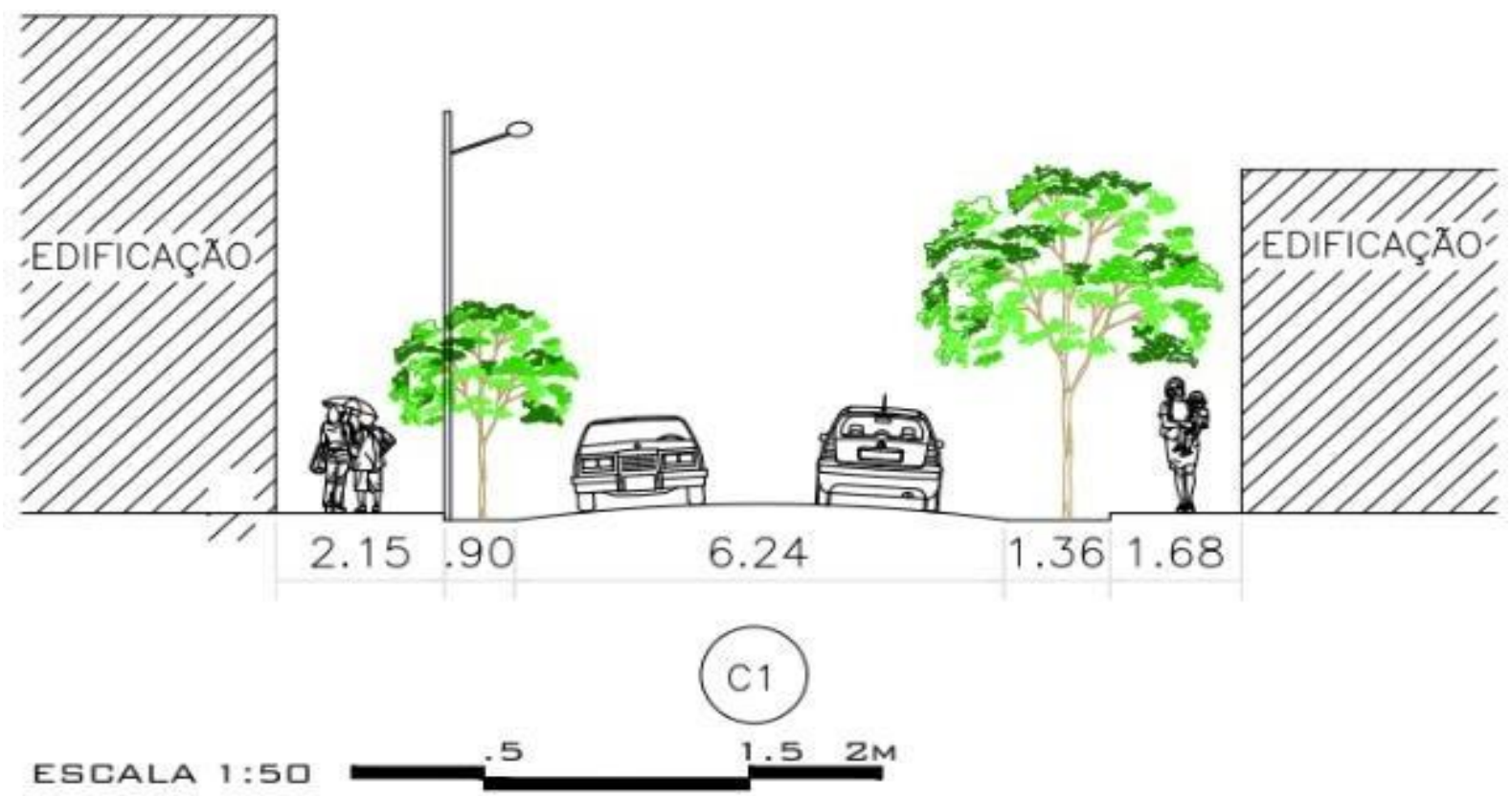

Fonte: Desenho do autor, 2019. 
As vias locais do bairro não possuem faixas de ciclistas, possuem um acostamento medindo de 01 (um) lado $1,36 \mathrm{~m}$ e do outro $0,90 \mathrm{~cm}$, que são utilizados pelos veículos para estacionamento, ao mesmo tempo em que em determinados trechos são compartilhados pela arborização e iluminação pública.

O fluxo de veículos da rua local se dá em dois sentidos. As faixas de veículos possuem 3,12m em cada lado, ou seja, elas possuem dimensões acima das estabelecidas pelo método de Mascaró (2005). A largura total da via local analisada é de $12,33 \mathrm{~m}$, ou seja, ela supera a largura total mínima e se aproxima da largura total ideal conforme o método de Mascaró (2005).

Desta forma, pode-se afirmar que as dimensões das faixas de tráfego de veículos automotivos da rua local analisada estão dentro dos padrões do método de Mascaró (2005), como também as calçadas atendem os limites mínimos descritos no método desse autor (2005), mas não estão totalmente de acordo com a NBR 9050(2015), pois não possuem o mesmo nivelamento de piso nas calçadas, piso tátil, rebaixamento de calçadas em travessia de pedestres, dentre outros pontos que são descritos na norma.

O acostamento é utilizado pelos veículos para estacionamento, ao mesmo tempo em que em determinados trechos são compartilhados pela arborização e iluminação pública. Os elementos calçadas e acostamentos, na rua local, analisada, são elementos que contribuem para o surgimento de consequências e conflitos na relação entre o tráfego de veículos nas vias locais e deslocamentos dos pedestres. Esses conflitos se dão nas demais vias do bairro, uma vez que estas possuem características semelhantes, com vias de circulação de veículos automotivos dentro dos padrões estabelecidos pelo método de Mascaró (2005).

Foi analisada somente uma rua local, que permite concluir que a dimensão das faixas de trânsito de veículos automotivos das demais vias locais encontra-se dentro dos padrões do método de Mascaró (2005), as calçadas encontram-se acima do limite mínimos e próximos do limite ideal do método de Mascaró (2005). As variações nas dimensões das calçadas e do acostamento determinam o nível do grau de conflito na relação tráfego de veículos automotivos e pedestres, nas vias locais do bairro, atualmente essa relação se dá de forma que, permite aos 
moradores e as pessoas que transitam pelas ruas do bairro, que se desloquem conforme suas necessidades de ir e vir.

As vias coletoras do bairro centro absorvem o fluxo do trânsito das ruas locais próximas a elas e o conduz a arterial principal. A via coletora Rua Cel. Guilherme Frantz é considerada como uma das coletoras do bairro pelo fato dela dar acesso ao Bairro Senhor Alexandre (onde se localiza o Hospital Municipal, Sub Estação Elétrica, Posto de Saúde, Campo de Futebol, Fórum), essa rua também concentra o Banco do Brasil, a sede do Ministério Público, a Escola Estadual de Ensino Médio Professora Francinet e dar acesso à rotatória e às Ruas Deputado José E. Estrela, José Nogueira da Silva (onde fica localizada a Prefeitura Municipal) e a rodovia PB 393, que liga o município de São João do Rio do Peixe a Estância Termal Brejo das Freiras e aos Municípios de Poço José de Moura, Santa Helena e outros.

A Rua Raimundo Barros absorve a circulação da via coletora Cel. Guilherme Frantz e distribui na via arterial principal. A rua coletora Padre Cicero absorve o trânsito coletado pela rua coletora Pedro Romão Dantas não pertencente ao Bairro Centro e o conduz a rua coletora Lucio Duarte que o conduz a outra rua coletora, a José Henrique Sobral, que distribui o fluxo do trânsito na via arterial principal, conforme apêndice $F$. No entanto salienta-se que esse percurso às vezes não é realizado desta forma pelos veículos automotivos, pois alguns condutores a depender de suas necessidades traçam outras rotas de circulação, conforme disposição da malha viária do bairro.

A análise da rua coletora Rua Cel. Guilherme Frantz foi realizada com base no método de Mascaró (2005), de acordo com a figura 3. 
Figura 3 - Características Físicas das Vias Coletoras.

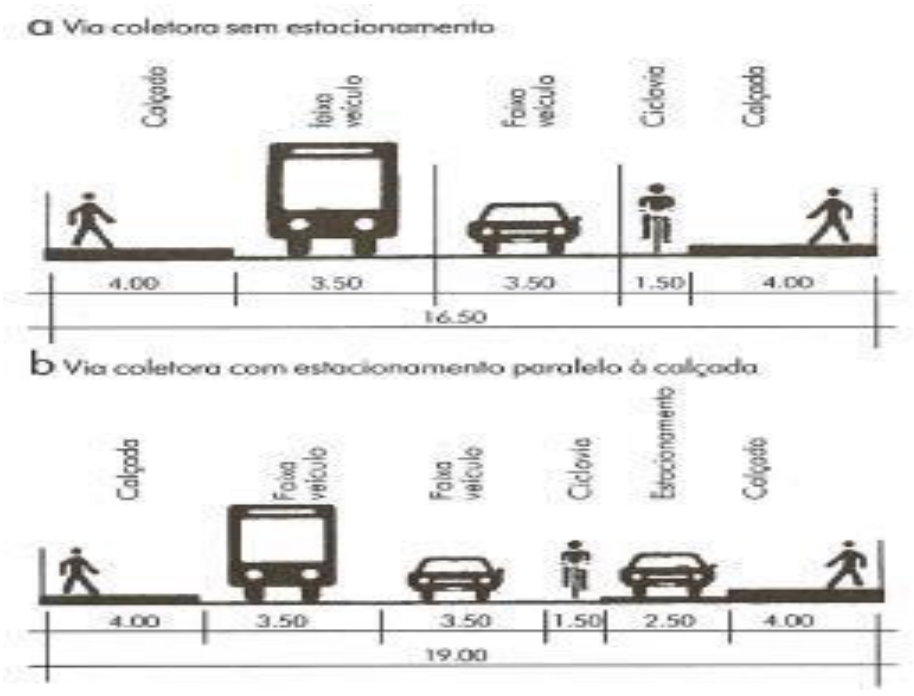

Fonte: MASCARÓ, 2005.

O corte realizado na via coletora Rua Cel. Guilherme Frantz demostra que a via coletora possui calçada de um lado medindo $2,15 \mathrm{~m}$, e do outro $3,08 \mathrm{~m}$, não atende assim os limites mínimos estabelecidos pelo método de Mascaró (2005).

A via coletora do bairro não possui faixa de ciclista, e sim um acostamento medindo de um lado $1,70 \mathrm{~m}$ e do outro $1,50 \mathrm{~m}$ que é utilizada pelos veículos automotivos para estacionamento, ao mesmo tempo em que é compartilhado pela arborização pública.

As faixas de veículos possuem 3,65m para cada faixa, ou seja, elas possuem dimensões acima das estabelecidas pelo método de Mascaró (2005). A largura total da via coletora analisada totaliza $15,73 \mathrm{~m}$. O fluxo de veículos da rua coletora se dá em dois sentidos.

Desta forma, pode-se afirmar que a dimensão das faixas de tráfego de veículos automotivos da rua coletora analisada está dentro dos padrões do método de Mascaró (2005), já as calçadas não possuem as dimensões para vias coletoras abordadas pelo referido método, ao mesmo tempo em que também não estão totalmente de acordo com a NBR 9050/2018, pois não possuem o mesmo nivelamento de piso nas calçadas, sinalização tátil, rebaixamento de calçadas em travessia de pedestres, dentre outros pontos descritos na norma. O acostamento é 
utilizado pelos veículos para estacionamento, ao mesmo tempo em que, em determinados trechos é compartilhado pela arborização e iluminação pública.

Outra via coletora que foi analisada é a Rua Raimundo Barros, pois essa rua apresenta situação atípica no trecho que fica localizado entre a Praça da Matriz e o calçadão que dar suporte ao convívio fraterno em período de festa da padroeira do município como também abriga parques de diversões e palco para eventos sociais públicos do município, haja vista, o município não possuir uma praça específica destinada aos grandes eventos, conforme figura 4.

Figura 4 - Via Coletora Rua Cel. Guilherme Frantz.

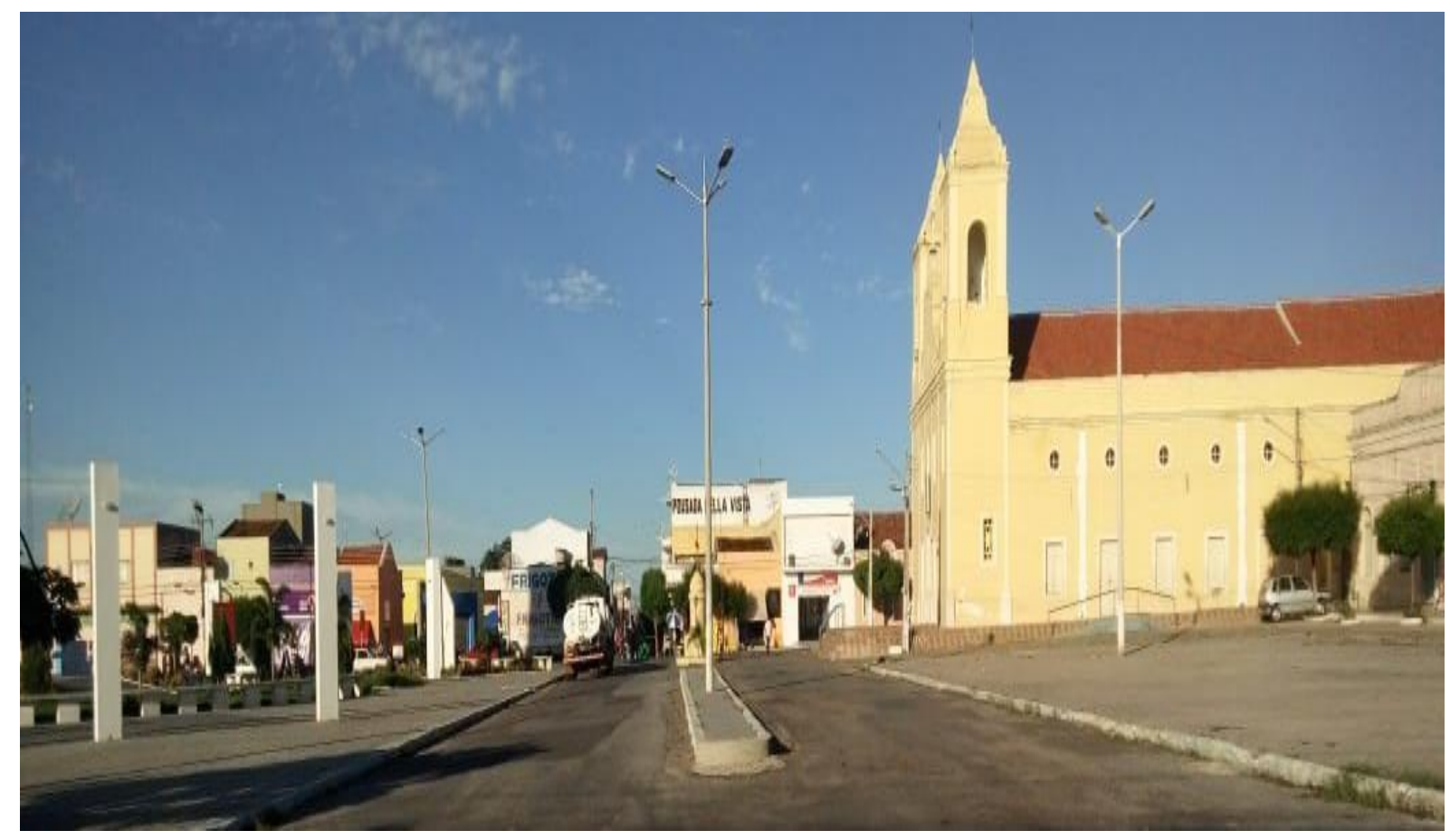

Fonte: Acervo pessoal, 2019.

Outro fator que contribui na escolha desse trecho da Rua Raimundo Barros é o fato dela cortar a Rua José Cândido Dantas, via arterial principal do barro e via pela qual passa a BR 405, que liga os Estados do Rio Grande do Norte ao da Paraíba, BR esta, pela qual passa a maior parte da escoação da produção de sal e outros produtos produzidos no Estado do Rio Grande do Norte. Esse transporte é realizado em sua maior partes por veículos de grande porte, cria assim, pontos de conflitos, na relação entre tráfego de transportes automotivos e pedestres na Rua 
José Cândido Dantas. Esses pontos de conflitos possuem oscilações variantes conforme o fluxo de veículos e pedestres.

Figura 5 - Características Físicas das Vias Coletoras.

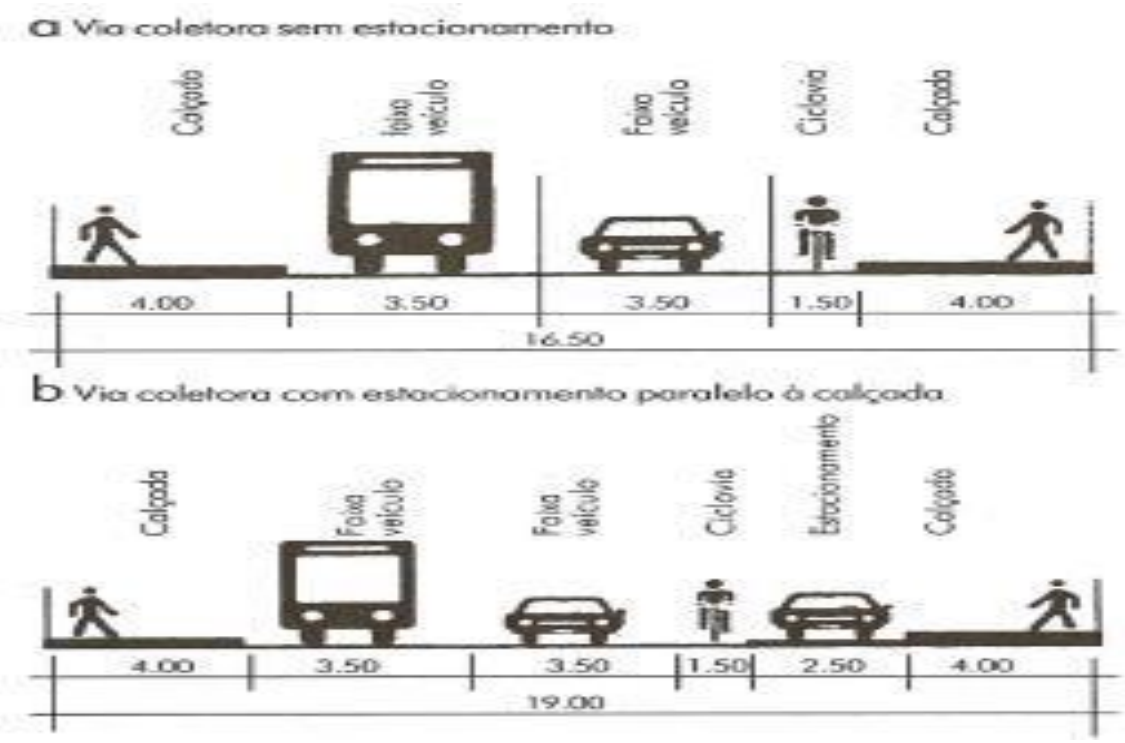

Fonte: MASCARÓ, 2005.

De um lado tem-se um calçadão de piso intertravado (que é utilizado pela igreja em período de festa para acomodar a parte social, e em outros períodos, pelo órgão público municipal para acomodar parques e palco para realização de festas).

Tem-se nesse trecho 02(duas) faixas de veículos 01(uma) medido 6,70m de largura, sentido esse que só vai veículos, $01(u m)$ canteiro central com iluminação pública medido 1,65m, (01) uma faixa de veículos medindo 7,05m de largura, sentido esse que só voltam veículos, essa faixa distribui o fluxo de veículos na via arterial principal do bairro, ao lado dessa via tem-se a Praça da Matriz, ponto nodal de entretenimento dos jovens do bairro e de toda zona urbana da cidade.

Essa praça está localizada nas proximidades da Igreja Nossa Senhora do Rosário, conforme mostra a figura 6 . Do terminal rodoviário, ponto de táxi, moto-táxi e próximo à saída para outros municípios, conforme anexo $\mathrm{E}$, esta via possui uma largura total de $15,40 \mathrm{~m}$ que atingi a largura mínima descrita no método de Mascaró (2005). 
Figura 6 - Rua Coletora Raimundo Barros.

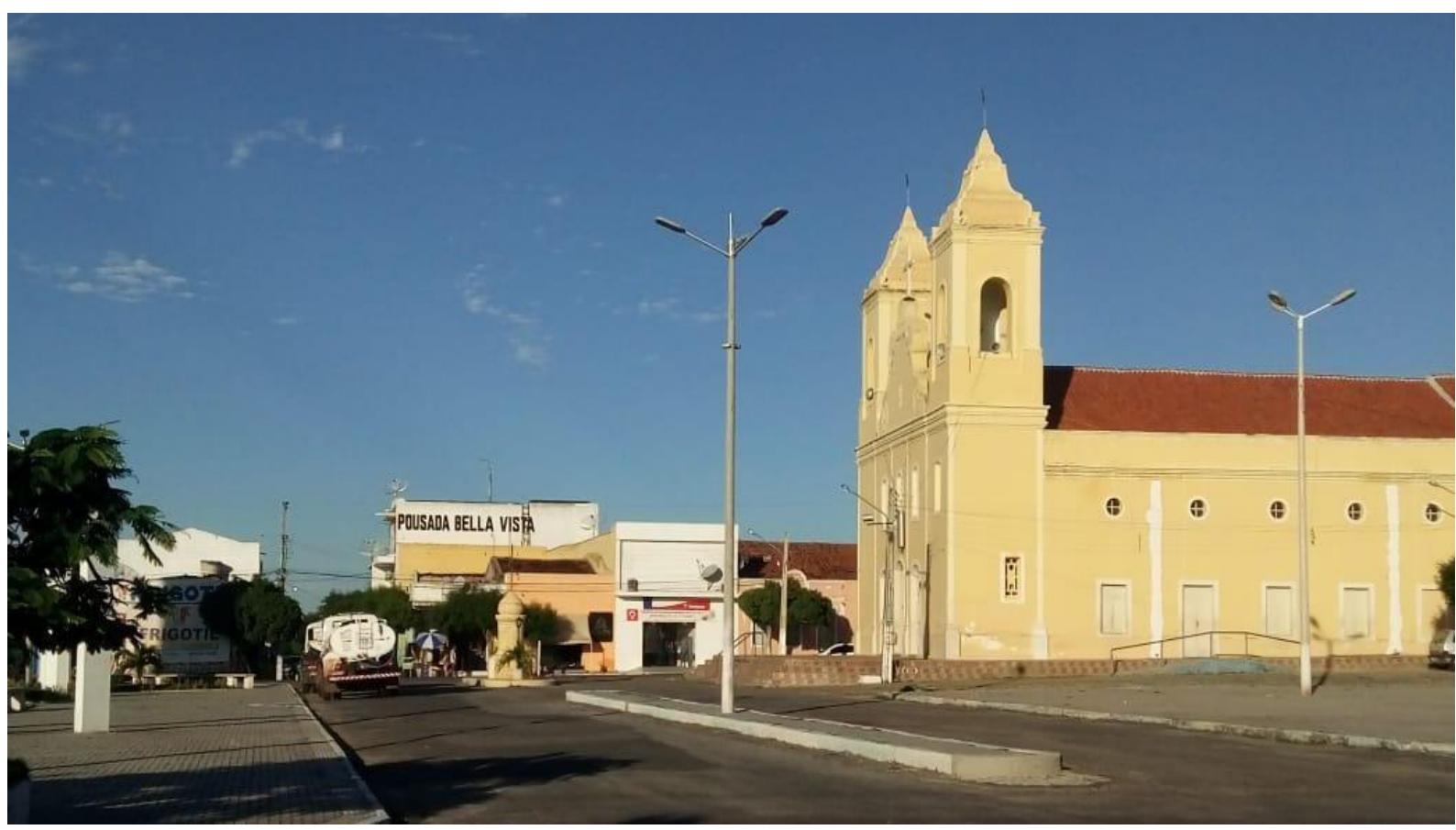

Fonte: Acervo pessoal, 2019.

A ausência do elemento acostamento no trecho analisado da Rua Raimundo Barros influencia no nível de conflitos e suas consequências na relação entre o tráfego de veículos e deslocamento de pedestres da referida rua. Esses conflitos se dão nas demais vias coletoras do bairro, uma vez que, as demais vias possuem características semelhantes, como circulação em dois sentidos dentro dos padrões estabelecidos pelo método de Mascaró (2005), calçadas e acostamento deficitários em graus de intensidades variantes, que não impossibilitam o convício entre o fluxo de veículos e pedestres nas ruas coletoras do bairro.

A via arterial principal do Bairro Centro da Cidade de São João do Rio do Peixe/PB, é a Rua José Cândido Dantas rua pela qual passar a BR 405, a qual possui variações nas dimensões dos elementos que a compõem.

Essa via é considerada arterial principal do bairro pelo fato dela concentrar: A maior parte do comércio do município; Ponto de taxi; Moto-táxi; Posto de gasolina; Terminal rodoviário; Praça da matriz; Igreja Nossa Senhora do Rosário; Agência dos Correios; Agência do Bradesco entre outros. 
O C4 realizado na Rua José Cândido Dantas, conforme apêndice J. Demonstra o local desse corte atravrés de 01 (uma) linha de chamada.

A via arterial principal do bairro possui calçada, de um lado, com a medida de $4,70 \mathrm{~m}$, e do outro, com $1,45 \mathrm{~m}$, atende assim os limites abordados pelo método de Mascaró (2005), nesse trecho somente de 01(um) lado da rua.

Essa rua não possui ciclovia, apenas um acostamento de ambos os lados medindo de um 2,60m e 1,45m respectivamente, que é utilizada pelos ciclistas, como também pelos veículos automotivos para estacionamento, ao mesmo tempo em que é compartilhada pela arborização pública em determinados trechos, neste ponto tem-se a presença de faixa de pedestre e lombada eletrônica.

Já as faixas de veículos são em (02) dois sentidos, possuindo 4,00m cada faixa, ou seja, elas possuem dimensões acima das estabelecidas pelo método de Mascaró (2005).

No entanto, em 1979 o DNER emitiu uma nova versão das instruções para o Projeto Geométrico Rural que determina a largura de $3,60 \mathrm{~m}$ em ambas às faixas para as rodovias federais, ou seja, legalmente a BR 405 encontra-se dentro das normas legais vigentes. Mas devido à disponibilização no mercado automobilístico de veículos cada vez maiores, a largura a ser considerada segura para se trafegar em BR's, que transitam veículos em 01(um) único sentido deve ser de $4.00 \mathrm{~m}$ e para BR's, que transitam veículos em 02 (duas) direções deve ser de $4.30 \mathrm{~m}$ por faixa. Um caminhão de fabricação recente mede $3,40 \mathrm{~m}$ de um retrovisor ao outro, e a distância recomendada de circulação entre dois caminhões é de $1,20 \mathrm{~m}$.

Levando-se em consideração uma realidade cada vez mais presente nas rodovias federais, que é o tráfego de veículos automotivos de grande porte, situação vivenciada pelo Bairro Centro da cidade de São João do Rio do Peixe/PB, fato constatado após várias visitas in loco, Essa rua possui 4,00m de largura em cada faixa de veículos, no entanto é privada em alguns trechos de seu uso total pela arborização pública, pela utilização do acostamento pelos veículos para estacionamento, que em alguns casos invadem parte da área de circulação destinada ao tráfego de veículos automotivos.

Outros fatores neste trecho da rua que influenciam no grau de intensidade no ponto de conflitos existentes são: Igreja Matriz Nossa Senhora do Rosário; Praça da 
Matriz de Nossa Senhora do Rosário; Terminal rodoviário; Posto de gasolina; Ponto de taxi e moto taxi; Agência do Banco do Bradesco e vários pontos de bar e ambulantes que durante o turno noturno aproveitam para venderem seus produtos, haja vista esse trecho ser ponto de encontro, entretenimento e diversão.

Todos esses fatores associados à forma de como se deu o processo de desenvolvimento da malha urbana do bairro centro, o dimensionamento incorreto das calçadas, e a ausência de uma faixa de ciclista, são fatores que fazem com que essa rua, especificamente nesse trecho, conviva com ponto conflitante com graus de intensidades diferentes, mesmo por ela possuir elementos positivos como: quebramolas ${ }^{16}$; faixas de pedestres e lombadas eletrônicas, respeitados por ambas as partes.

Desta forma pode-se afirmar que a relação entre tráfego de veículos e pedestres, neste trecho da rua, se dá de forma problemática e exigem das partes envolvidas atenção e cuidados para que todos desfrutem do direito de ir e vir conforme as suas necessidades.

O C4 da via arterial principal á Rua José Cândido Dantas está localizado em um trecho da rua onde existe um ponto conflitante.

A análise deste trecho foi realizada com base no método abordado na metodologia de Mascaró (2005), conforme figura 7, e com as normas do DNIT (2010) e do DNER (1979).

Figura 7 - Características Físicas da Via Arterial.

Vio orterial sem estocionomento

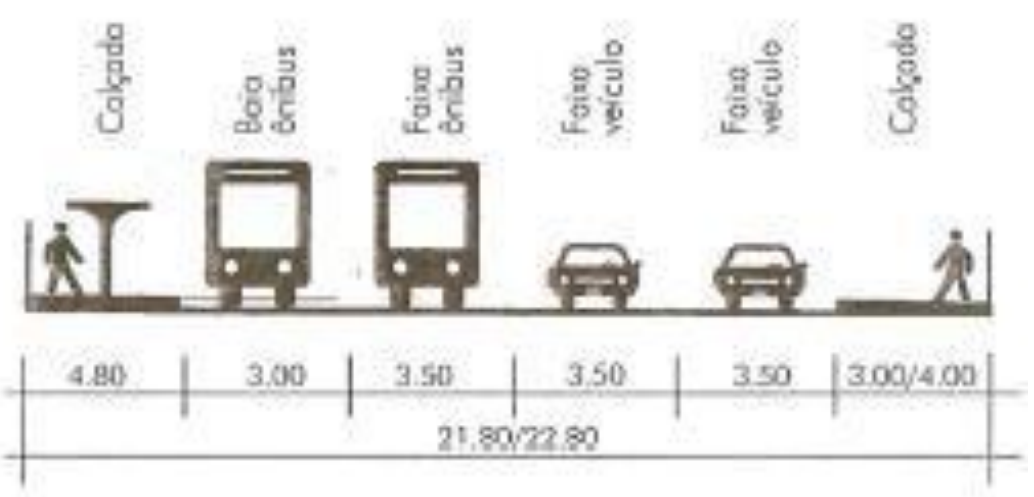

Fonte: MASCARÓ, 2005. 
O C5 realizado na Rua José Cândido Dantas. Demostra que esse trecho da rua possui as mesmas características elencadas no $\mathrm{C} 4$.

Figura 8 - C5 da Via Arterial Principal Rua José Cândido Dantas.

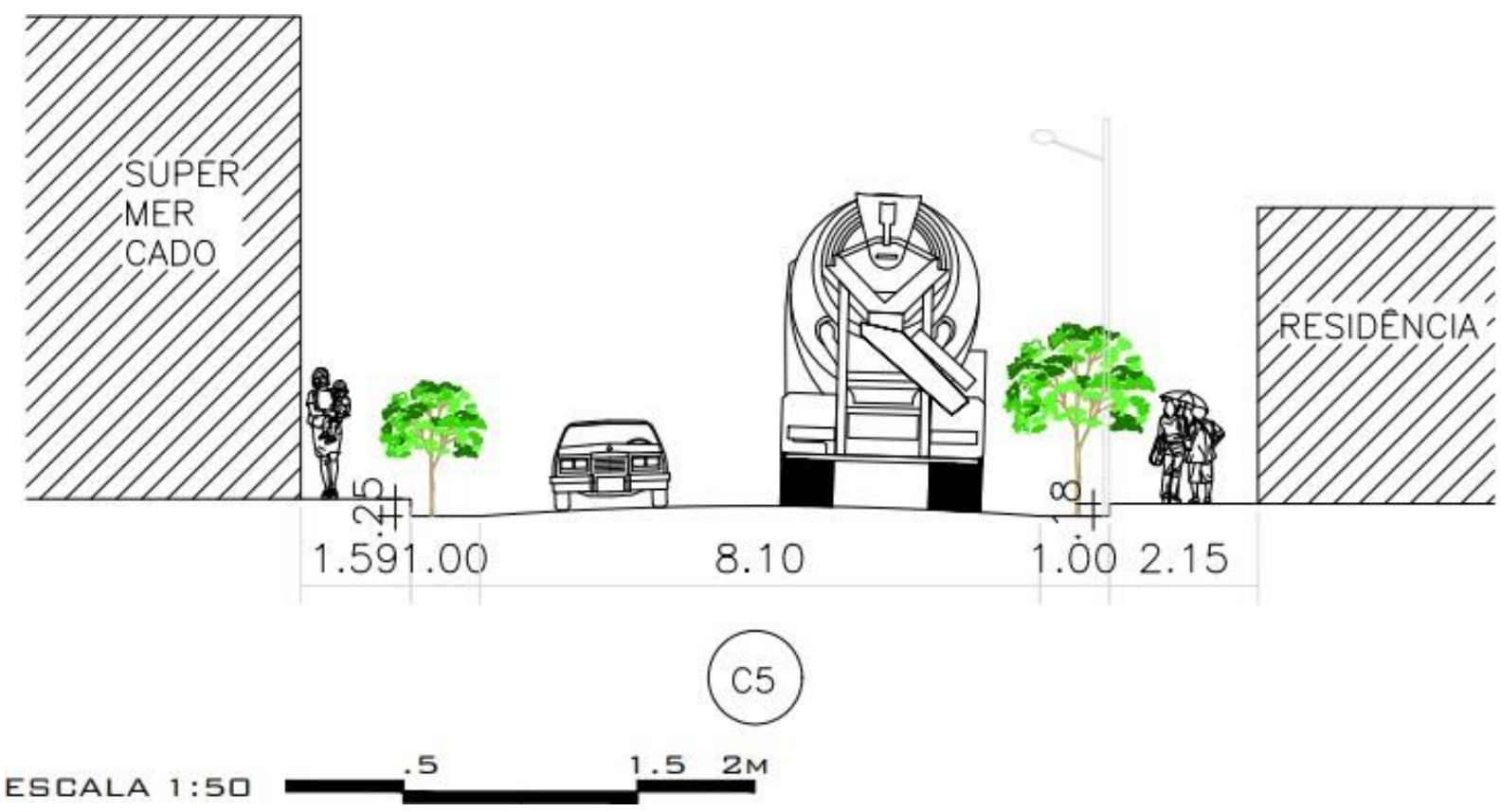

Fonte: Desenho do autor, 2019.

As dimensões de seus elementos são as seguintes: Calçada medindo $1.59 \mathrm{~m}$ e do outro $2.15 \mathrm{~m}$, não atende assim, os limites estabelecidos pelo método de Mascaró (2005) para este tipo de via, acostamento de ambos os lados medindo $01 \mathrm{~m}$. Já as faixas de veículos se dão em dois sentidos, possuem 4,05m de largura cada, ou seja, elas possuem dimensões acima das estabelecidas pelo método de Mascaró (2005) e pelo o DNER (1979).

No entanto, vale salientar que neste trecho constata-se a presença de faixa de pedestre e existência paralela em ambos os lados da rodovia de arborização pública que impõe obstáculo natural temporário às dimensões disponíveis para tráfego de veículos, principalmente os de grande porte.

Neste trecho da rua está instalado o Enéas supermercado, o maior comércio deste ramo da zona urbana do município, ou seja, nas visitas in loco realizadas observou-se que é considerável o fluxo de clientes que realizam suas compras no 
supermercado, pelo fato do supermercado não possui estacionamento próprio, desta forma é rotineiro os condutores de veículo estacionarem no acostamento da Rua José Cândido Dantas, para realizarem suas compras, a duração do estacionamento varia bastante, o que acarreta transtorno no fluxo de veículos da Rua José Cândido Dantas. Conforme mostra figura 9.

Figura 9 - Localização do Supermercado Eneas.

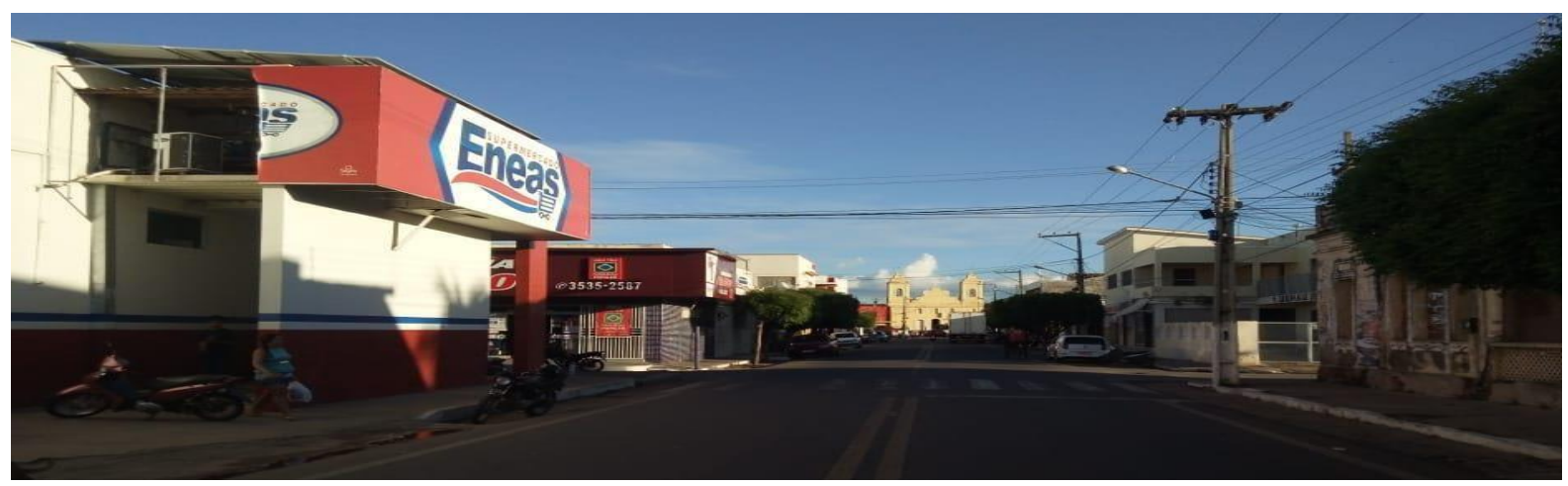

Fonte: Acervo pessoal, 2019.

A análise deste trecho foi realizada com base no método abordado na metodologia de Mascaró (2005), e com as normas estabelecidas pelo DNIT (2010) e pelo DNER (1979).

Figura 10 - Características Físicas da Via Arterial.

a Vo orterial sem estocionomento

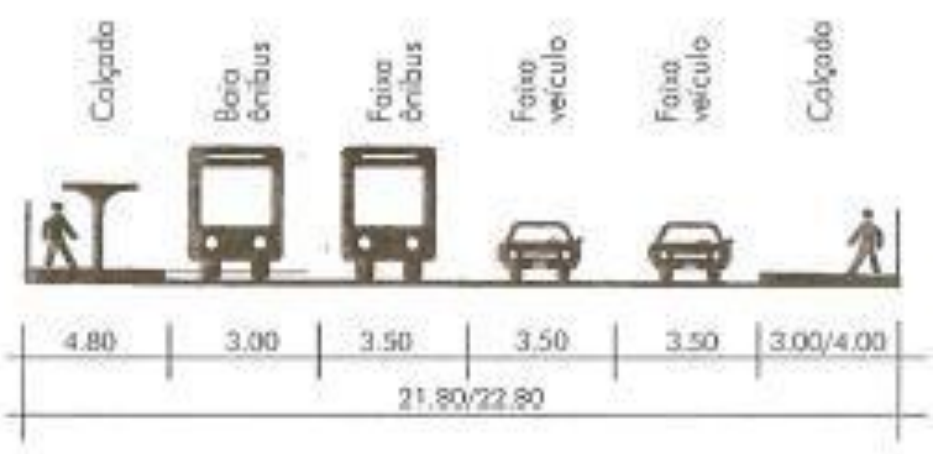

Fonte: MASCARÓ, 2005. 
O C6 analisado na via arterial principal da Rua José Cândido Dantas conforme apêndice L. Demostra que, neste trecho, esta possui as características semelhantes às elencadas no $\mathrm{C} 4 \mathrm{e} \mathrm{C} 5$. Conforme figura 11.

Figura 11 - C6 da Via Arterial Principal Rua José Câdido Dantas.

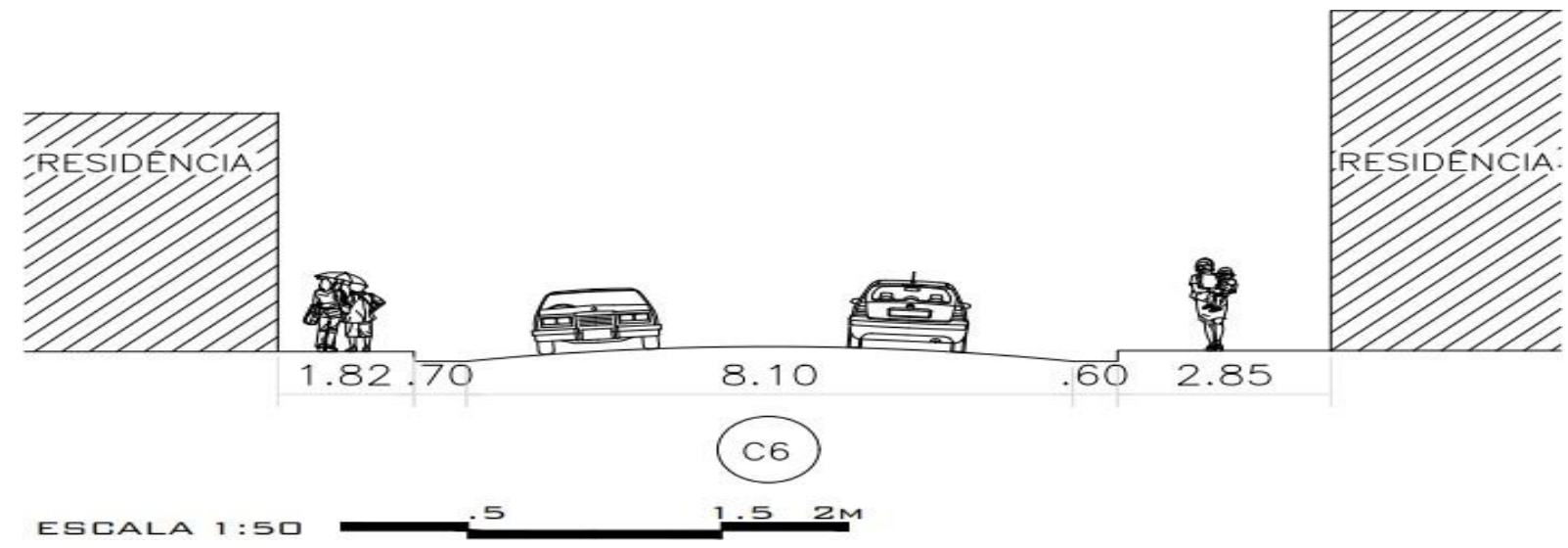

Fonte: Desenho do autor, 2019.

As dimensões de seus elementos são: calçada de um lado medindo $1.82 \mathrm{~m}$, de do outro $2.85 \mathrm{~m}$, não atendendo assim os limites abordados no método de Mascaró (2005) para este tipo de via, acostamento medindo de um lado $0.70 \mathrm{~cm}$ e do outro $0.60 \mathrm{~cm}$. Já as faixas de veículos possuem duas direções medindo $4,05 \mathrm{~m}$ em cada faixa, ou seja, elas possuem dimensões acima das estabelecidas pelo método de Mascaró (2005) e pelo o DNER (1979).

Neste trecho da rua existe presença da faixa de pedestres, não existe presença de arborização pública, no entanto vale salientar que esse trecho é cortado pela Rua local José Bernardino Batista que ao oeste dá acesso ao bairro habitacional $\mathrm{Pe}$. Galberto e ao leste à rotatória e às Ruas Deputado José E. Estrela, José Nogueira da Silva (onde fica localizada a Prefeitura Municipal) e a PB 393, que liga o município de São João do Rio do Peixe/PB a Estância Terminal Brejo das Freiras e aos Municípios de Poço José de Moura, Santa Helena e outros. Conforme figura 12. 
Figura 12 - Local do C6 na Via Arterial Principal do Bairro Rua José Cândido Dantas.

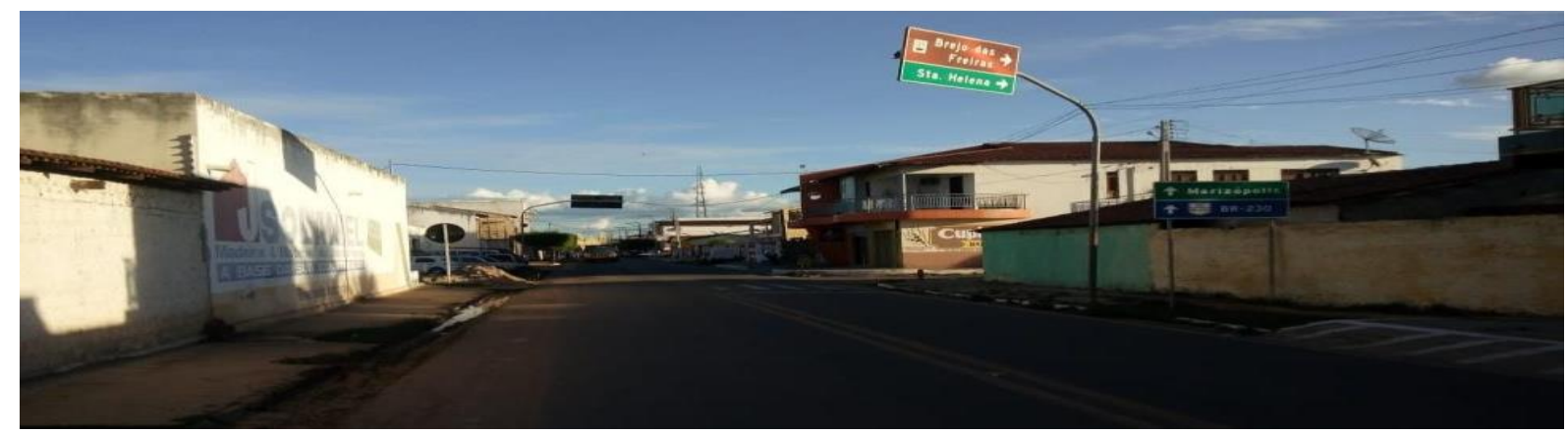

Fonte: Acervo pessoal, 2019.

Caracteriza-se assim um fluxo fluente continuo de veículos automotores e um ponto de conflito nesse local com graus de intensidade variantes, conforme o dia e horário, a faixa de pedestres se apresente nesse trecho da Rua José Cândido Dantas, conforme mostra a figura, 12 acima.

Após a análise das vias locais e coletoras conforme método de Mascaró (2005), e a via arterial principal acrescido das normas do DNIT (2010) e do DNER (1979), pode-se afirmar que: as vias locais do bairro centro da cidade de São João do Rio do Peixe/PB possuem calçadas dentro dos limites mínimos abordado pelo método de Mascaró (2005), estas não possuem ciclovias. Possuem um acostamento que é compartilhado pelos ciclistas, pela arborização pública e pelos veículos automotivos para estacionamento. As faixas destinadas à circulação de veículos automotivos estão dentro dos padrões descritos no método de Mascaró (2005). Mas não estão totalmente de acordo com a NBR 9050 (2015), como por exemplo: nivelamento entre as calçadas; sinalização tátil, rebaixamento de calçadas em travessia de pedestres e outros pontos, mas elas possibilitam o convívio diário entre pedestres e veículos automotivos nas vias locais do bairro.

As vias coletoras do bairro centro da cidade de São João do Rio do Peixe/PB, no C2 não possuem calçadas dentro dos limites abordados pelo método de Mascaró (2005). No C3 o trecho analisado é atípico, pois a rua analisada assume neste trecho a função de uma via coletora e na sua continuação assume a função de via local, ambas as vias analisadas não possuem ciclovias, possuem um acostamento 
que é compartilhado pelos ciclistas, pela arborização pública e pelos veículos automotivos para estacionamento. As faixas destinadas à circulação de veículos automotivos estão dentro dos padrões descritos no método de Mascaró (2005) mesmo elas não estando totalmente de acordo com a NBR 9050 (2015), como por exemplo: O nivelamento entre as caldadas; sinalização tátil, rebaixamento de calçadas em travessia de pedestres e outros pontos, mas elas possibilitam de forma deficitária o convívio diário entre pedestres e veículos automotivos.

A via arterial principal do bairro centro da cidade de São João do Rio do Peixe/PB a Rua José Cândido Dantas pela qual passa a BR 405, apresenta variações consideráveis nas dimensões de seus elementos, no item calçadas nos 03(três) cortes analisados C4, C5 e C6, somente no C4 a calçada encontra-se dentro dos limites abordados pelo método de Mascaró (2005), a rua em toda sua extensão não possui ciclovia, as faixas de veículos se dão em 02(dois) sentidos C4, C5 e C6 estão dentro dos limites abordados pelo método de Mascaró (2005), que é de 3,50m de largura e dos limites estabelecidos pelo DNER (1979), que foi de 3,60m para BR que há tráfego em 02 (dois) sentidos, no entanto o tráfego pela Rua José Cândido Dantas se dar de forma deficitária por alguns fatores que atuam na relação viária da referida rua, dos quais se elenca como fator principal a BR 405 que passa por ela.

A passagem da BR 405 promove benefícios ao comércio do bairro centro através do fluxo contínuo de veículos e pessoas, ao mesmo tempo em que promove alterações no bem estar e na segurança do bairro, Essa dualidade promovida pelo conflito entre o espaço viário e o espaço urbano gera impactos no papel operacional da via, no uso e ocupação do solo urbano e consequências ao bairro como: aumento da poluição visual com a inclusão de elementos do sistema viário rodoviário, elevação do índice de gases e ruídos promovidos do fluxo de veículos automotivos a ocasionar baixa no índice de qualidade de vida do bairro centro da cidade de São João do Rio do Peixe/PB. 


\section{CONCLUSÃO}

Para este fim, a história referente ao urbanismo, infraestrutura urbana, malha viária e as normas que regulamentam o sistema viário, como também a origem e o desenvolvimento da malha viária do município foram fundamentais, sobretudo no trabalho de Mascaró (2005), que auxiliou e fundamentou o método de análise utilizado, o qual se mostrou satisfatório às necessidades da pesquisa e para se alcançar os objetivos do estudo.

Com o propósito de obter-se os objetivos da pesquisa, utilizou-se o software (Autocad) para a elaboração de redesenho das vias em formato de corte, que foram analisados e comparados com o método de Mascaró (2005) e embasadas pelas normas do DNIT (2010) e do DNER (1979), obteve-se resultados os quais demostram que os elementos físicos que compõem as vias locais e coletoras do bairro centro da cidade de São João do Rio do Peixe/PB, encontram-se dentro dos padrões abordados pelo método utilizado na análise, mas não totalmente de acordo com normas vigentes, ao ponto de inviabilizem o deslocamento dentro do bairro, caracterizando nessas vias como deficitária e aspirante de cuidados, principalmente por parte dos pedestres que circulam por elas.

A análise da via arterial principal do bairro centro da cidade de São João do Rio do Peixe/PB, a Rua José Cândido Dantas, revelou que, por esta via passa BR 405 que liga o Estado do Rio Grande do Norte ao Estado da Paraíba, a mesma possui elementos físicos que a compõem com dimensões variantes, e que em determinados trechos incidem sobre ela agravantes advindos do próprio sistema viário e alheio a ele, que interferem na malha viária da via, e promovem consequências como: Aumento da poluição visual; Elevação do índice de gases e ruídos; Perca da qualidade de vida no bairro; Agravamento dos pontos conflitantes que atuam na via arterial e no bairro centro com grau de intensidade variante conforme dia e horário.

Faz-se necessário aprofundar o estudo sobre a relação entre a malha viária e o deslocamento dentro do bairro ou na zona urbana, de modo a enfocar outros 
aspectos relevantes, como por exemplo: As transformações na malha urbana e nas linhas de desejos da população, que se modificam conforme suas necessidades.

Agregar à pesquisa a natureza quantitativa do fluxo de tráfego que flui pela via arterial principal do bairro pelo qual passa a BR 405.

Detalhar mais como se dar a relação entre sistema viário e o deslocamento pelas vias do bairro. Diante do exposto essa pesquisa poderá servir de base para estudo mais aprofundado sobre o sistema viário, seja ele em uma cidade de pequeno ou grande porte.

\section{REFERÊNCIAS BIBLIOGRÁFICAS}

BAENINGER, Rosana. População e cidades: subsídios para o planejamento e para as políticas sociais. UNICAMP, 2010.

BRAGA, Roberto; CARVALHO, Pompeu Figueiredo de. Cidade: espaço da cidadania. Pedagogia cidadã: cadernos de formação: ensino de Geografia. São Paulo: UNESP-PROPP, 2004. p. $105-120$.

BRASIL. DNIT. Manual de projeto geométrico de travessias urbanas. Rio de Janeiro: DNITInstituto, 2010.

CARVALHO, Patrícia Felipe de Sousa. Crescimento urbano da cidade de Sousa - PB e sua contribuição da degradação ambiental do rio Peixe. 2015. 43 f. Monografia (Licenciatura em Geografia) - Universidade Federal de Campina Grande. Cajazeiras, 2015.

DUARTE, Fábio. Planejamento urbano. São Paulo: Editora Ibpex, 2009.

GALVÃO, Rogerio Candido Ramalho. São João do Rio do Peixe - Datas e Notas. Terezinha: Ed. Hall S. A., 2011.

INSTITUTO BRASILEIRO DE GEOGRAFIA E ESTATÍSTICA. 2010. Resultado dos Dados do Censo - 2010. Disponível em: <www.ibge.gov.br>. Acesso em setembro de 2017.

INSTITUTO BRASILEIRO DE GEOGRAFIA E ESTATÍSTICA. 2017. Resultado dos Dados Preliminares do Censo - 2017. Disponível em: <www.ibge.gov.br>. Acesso em setembro de 2017.

INSTITUTO BRASILEIRO DE GEOGRAFIA E ESTATÍSTICA, 2018. Resultado dos Dados Preliminares do Censo - 2017. Disponível em: <https://cidades.ibge.gov.br/brasil/pb/sao-joaodo-rio-do- peixe/panorama>. Acesso em novembro de 2018.

INSTITUTO BRASILEIRO DE GEOGRAFIA E ESTATISTICA. Paraíba: São João do Rio do Peixe. Disponível em: <https://cidades.ibge.gov.br/painel/historico70\&search=||infogr\%E1ficos:hist\%F3rico> Acesso em: 25 de outubro de 2017.

LEITE, Carlos. Cidades sustentáveis, cidades inteligentes: desenvolvimento sustentável num planeta urbano. Porto Alegre, 2012. Bookman, v. 1, p. 8-264. 
MASCARÓ, Juan Luis. Infraestrutura Urbana para o Século XXI. 4. ed. [s.n.], 2006.

MASCARÓ, Juan Luis. Loteamentos urbanos. 4. ed. [s.n.], 2005.

SILVA, Wellington Rafael da. Desenvolvimento urbano e regional da/na Cidade de ArarunaPB. 2013.

SILVEIRA, Maria da Graça Valle. Análise de rede viária urbana: caso de estudo: a cidade de Campo Bom. 1994. 